\title{
Place Matters! Fostering place-based geoscience teaching at the University of Hawai'i at Mānoa
}

\author{
Daniela Böttjer-Wilson ${ }^{1}$, Barbara C. Bruno \\ ${ }^{1}$ Center for Teaching Excellence, Office of Faculty Development and Academic Support, \\ University of Hawai' $i$ at Mānoa, Honolulu, Hawai' $i$, USA, ${ }^{2}$ Hawai'i Institute of Geophysics \\ and Planetology, School of Ocean and Earth Science and Technology, University of \\ Hawai'i at Mānoa, Honolulu, Hawai'i, USA.
}

\begin{abstract}
Drawing on the importance of place has been shown to be a powerful tool in education. This paper explores place-based teaching (PBT) in geoscience courses at the University of Hawai ' $i$ at Mānoa's School of Ocean and Earth Science and Technology, where faculty and student demographics sharply differ. Despite these differences, survey results from geoscience faculty $(n=59)$ and students $(n=83)$ revealed a strong consensus: $78 \%$ of students and $83 \%$ of faculty reported that PBT is an important and effective practice to reach all students. Most faculty (91\%) indicated that they currently incorporate at least some PBT practices in their geoscience classes and would like to incorporate additional ones in the future. However, many faculty expressed concern about lack of knowledge or resources, particularly regarding PBT strategies that require a high level of cultural competency. We therefore propose a three-layered PBT framework, where faculty can start with more accessible PBT strategies (the base layer) and progress upwards as their cultural competency deepens. Through providing geoscience resources and professional development opportunities, we can empower faculty to include more diverse and culturally meaningful practices as their experience and knowledge deepens.
\end{abstract}

Keywords: Place-Based Teaching; Culture; Indigenous; Geoscience; Ocean, Earth, and Environmental Science; Hawai 'i. 


\section{Introduction}

Place-Based Teaching (PBT) can be defined as using place, people, and its resources (e.g., linguistic, cultural, or environmental) as foundation for learning. Widely considered as powerful pedagogical approach across disciplines and grade levels (e.g., Elder 1998, Sobel 2004), PBT yields many positive student outcomes, such as increasing interest and motivation (Smith and Sobel 2010); strengthening place attachment (Semken and Butler Freeman 2008); promoting strong relationships with local communities (Sobel 2004); and cultivating environmentally conscientious citizens (Stapp et al. 1969). Whereas PBT can be a successful approach for engaging all students, it has been shown to be exceptionally effective with indigenous students (e.g., Cajete 1994, Semken et al. 2017). In studies specific to geoscience (defined here as ocean, earth and environmental science), bridging traditional indigenous knowledge with Western science and community needs has been shown to increase students' interest by promoting learning rooted in indigenous history, community, culture and language while preserving students' cultural identity (e.g., Reano and Ridgway 2015, Smythe et al. 2017). In Hawai' $i$, geoscience professors have found a variety of ways to integrate indigenous and Western knowledge, such as having kupuna (elders) co-lead fieldtrips (Gibson and Puniwai 2006), accessing historical weather data from Hawaiian newspapers (Businger et al. 2017), and developing curriculum focused on people \& relationships and place \& culture (Lemus et al. 2014). The University of Hawai'i (UH) at Mānoa has a highly diverse enrollment, including 16\% Native Hawaiians and Pacific Islanders (NHPI). However, these indigenous students comprise only 7\% of School of Ocean and Earth Science and Technology (SOEST) students (IRAO, 2019). This underrepresentation in geoscience majors is surprising given that NHPI thrived as ethnogeoscientists for centuries (e.g., Lincoln \& Vitousek 2017), and raises several questions: Does PBT appeal to current SOEST students and faculty? Might PBT attract more indigenous students to SOEST? How can we support faculty who want to incorporate more PBT into their classrooms? These are some of the questions we tackle in this study.

\section{Methods}

In Spring 2018, we created two online surveys with a mix of multiple-choice, Likert scale and open-ended questions to acquire information and perceptions from faculty and students about PBT in SOEST classes (Table 1). Our approach focuses on student and faculty perceptions and differs from studies which evaluate perceived benefits of PBT (e.g., Semken and Butler Freeman 2008). The protocol was approved as exempt by the UH Institutional Review Board (\#2018-00399). During Fall 2018, we emailed SOEST teaching faculty $(n=120)$ and students $(n=276)$ with a request to complete the respective surveys. Surveys were open for three weeks, during which two reminders were sent. $49 \%$ of faculty 
$(n=59)$ and $29 \%$ students $(n=81)$ responded. Data were analyzed with the SurveyMonkey data analysis software.

\section{Table 1. Faculty and Student Survey Questions}

A) Faculty Survey Questions (13 total)

1. Place-Based Teaching (PBT) is a pedagogical approach that can be defined as using place and its resources (e.g., linguistic, cultural, historical, spiritual, environmental, or physical) as a foundation for learning across disciplines. Is there anything that you would like to add or change to this definition of PBT? (OE)

2. $\mathrm{PBT}$ in Hawai' $\mathrm{i}$ is an important and effective strategy to reach: (MC)

3. Which instructors should use PBT when teaching in SOEST? (MC)

4. Which PBT approaches do you currently use in your teaching, if we define "place" as Mānoa, O'ahu, Hawai'i or the Pacific region? (MC-all)

5. Which PBT strategies do you not currently use in your teaching but would like to in the future? (MC-all)

6. On a scale of 1 to 5 , with 5 being very comfortable and 1 being very uncomfortable, how would you rate your level of comfort in incorporating the following PBT strategies into your teaching: (L5)

7. Have you participated in any professional development training with regard to PBT practices and strategies?

8. What SOEST lab and lecture classes have you taught in the past 3 years? (MC-all)

9. What level are these SOEST lab and lecture classes? (MC- all)

10. Where are you from (born and/or raised)? (MC)

11. What best describes your gender? (MC)

12. What is your ethnic origin? (MC-all)

13. Is there anything else that you would like to add about place-based teaching? (OE)

\section{B) Student Survey Questions (14 total)}

1. What is your current status in SOEST? (MC)

2.-3. Same as Faculty Question 2-3

4. What $\%$ of your SOEST lab and lecture classes have incorporated strong ties to place in the curriculum, if we define "place" as Mānoa, O‘ahu, Hawai‘i or the Pacific region? (MC)

5. In what SOEST disciplines were these place-based lab and lecture classes? (MC-all)

6. What level were these SOEST lab and lecture classes? (MC-all)

7. What aspects of PBT were included in these SOEST place-based lab and lecture classes? (MC- all)

8. Please select the answer that best indicates your agreement or disagreement with the following statement: "SOEST lab and lecture classes with strong ties to place (Mānoa, $O$ 'ahu, Hawai ' $i$ or the Pacific region) have greatly improved my learning experience" (L5)

9. Please select the answer that best indicates your agreement or disagreement with the following statement: "SOEST lab and lecture classes and courses with strong ties to place (Mānoa, O'ahu, Hawai' $i$ or the Pacific region) have significantly increased my interest in pursuing a major and/or career in the Earth, Ocean, and Environmental Sciences" (L5)

10. What aspects of PBT would you like to see included in your SOEST lab and lecture classes in future semesters? (MC- all)

11.-14. Same as Faculty Questions 10-13

Codes: $(\mathrm{OE})=$ open-ended; $(\mathrm{L} 5)=5$-point Likert-scale; $(\mathrm{MC})=$ Multiple Choice - single response required; $(\mathrm{MC}$ all $)=$ Multiple Choice - check all that apply. 


\section{Survey Results}

The 81 student respondents included undergraduate (43\%) and graduate students $(53 \%)$. About one-third (35\%) were from Hawaii or the Pacific, $41 \%$ from the US mainland, and $24 \%$ from other countries. Most (54\%) of the 59 faculty respondents were from the US mainland, with $34 \%$ from abroad and only 13\% from Hawaii or the Pacific. Faculty were predominantly Caucasian (79\%), with $18 \%$ Asian, 2\% NHPI and 6\% reporting at least one other ethnicity. Students were $61 \%$ Caucasian, 38\% Asian, 9\% NHPI, and $21 \%$ reporting at least one other ethnicity. (Totals exceed $100 \%$, as respondents can select multiple ethnicities.). Faculty were mostly male (57\%), whereas students were mostly female $(66 \%)$. In summary, student respondents were more likely to be "local" (from the HawaiiPacific region), ethnically diverse and female. Faculty were more likely to be non-local (from the US or abroad), Caucasian and male. Students overwhelmingly reported that courses with strong ties to place "greatly improved my learning experience" (81\% agreed /strongly agreed vs. 3\% disagreed/strongly disagreed) and "significantly increased my interest in pursuing a major and/or career" in the geosciences (75\% agreed/ strongly agreed vs. $1 \%$ disagreed /strongly disagreed). All (100\%) students reported they would like to see more PBT in SOEST courses. When asked "what aspects of PBT would you like to see included in your SOEST lab and lecture classes in future semesters?" all PBT strategies were popular; most voted for more field trips (81\%) and least desired are community workdays (46\%; Table 2). Survey results indicated strong support among both students and faculty for PBT: $78 \%$ of student and $83 \%$ of faculty respondents reported that PBT is an important and effective practice to reach all students. With the majority of SOEST faculty being non-local, we were interested in finding out from both groups which instructors they believe should use PBT. The vast majority of faculty $(69 \%)$ and students (78\%) responded that all instructors should teach in the context of place: very few faculty (3\%) and students $(13 \%)$ indicated that only local and/or indigenous instructors should use PBT. Several faculty and students noted that which instructors should use PBT depends on their expertise and subject matter - not their ethnic background or birthplace. The vast majority of faculty (91\%) reported using some PBT practices in their SOEST classes. There is broad general agreement between faculty and student responses on what types of PBT are currently being used, with local/regional data sets being the most common (Table 2). Relatively few faculty reported incorporating indigenous knowledge or ways of knowing (33\%), cultural practices $(24 \%)$, service learning $(19 \%)$, or community workdays $(10 \%)$ into their classes. Interestingly, approximately half of students (44\%) and faculty (47\%) reported that Hawaiian language terms were used, although the extent or efficacy is unclear. 
Table 2. Summary of survey responses regarding place-based teaching (PBT) in SOEST, and faculty comfort level in using these practices.

\begin{tabular}{|c|c|c|c|c|c|}
\hline & \multicolumn{2}{|c|}{ Student Survey Responses } & \multicolumn{3}{|c|}{ Faculty Survey Responses } \\
\hline $\begin{array}{l}\text { Answer Choices } \\
\text { (check all that } \\
\text { apply) }\end{array}$ & $\begin{array}{c}\text { Q7 } \\
\text { What aspects } \\
\text { of PBT were } \\
\text { included in } \\
\text { these SOEST } \\
\text { place-based lab } \\
\text { and lecture } \\
\text { classes? }^{1}\end{array}$ & $\begin{array}{c}\text { Q10 } \\
\text { What aspects } \\
\text { of PBT } \\
\text { would you } \\
\text { like to see } \\
\text { included in } \\
\text { your SOEST } \\
\text { lab and } \\
\text { lecture } \\
\text { classes in } \\
\text { future } \\
\text { semesters? }\end{array}$ & $\begin{array}{c}\text { Q4 } \\
\text { Which PBT } \\
\text { approaches do } \\
\text { you currently } \\
\text { use in your } \\
\text { teaching, if we } \\
\text { define "place" } \\
\text { as Mānoa, } \\
\text { O‘ahu, Hawai'i } \\
\text { or the Pacific } \\
\text { region?' }\end{array}$ & $\begin{array}{c}\text { Q6 } \\
\text { How would } \\
\text { you rate your } \\
\text { level of } \\
\text { comfort in } \\
\text { incorporating } \\
\text { the following } \\
\text { PBT } \\
\text { strategies into } \\
\text { your } \\
\text { teaching? }\end{array}$ & $\begin{array}{c}\text { Q5 } \\
\text { Which PBT } \\
\text { strategies do } \\
\text { you not } \\
\text { currently use } \\
\text { in your } \\
\text { teaching but } \\
\text { would like to } \\
\text { in the } \\
{\text { future }{ }^{1}}^{1}\end{array}$ \\
\hline $\begin{array}{l}\text { Local/regional } \\
\text { data sets }\end{array}$ & $91 \%$ & $70 \%$ & $79 \%$ & 4.6 & $9 \%$ \\
\hline $\begin{array}{l}\text { Local/regional } \\
\text { experts as guest } \\
\text { speakers }\end{array}$ & $43 \%$ & $69 \%$ & $59 \%$ & 4.5 & $16 \%$ \\
\hline Field trips & $76 \%$ & $82 \%$ & $53 \%$ & 4.3 & $17 \%$ \\
\hline Service learning & $19 \%$ & $51 \%$ & $19 \%$ & 3.5 & $29 \%$ \\
\hline $\begin{array}{l}\text { Community } \\
\text { workdays }\end{array}$ & $19 \%$ & $46 \%$ & $10 \%$ & 3.3 & $26 \%$ \\
\hline $\begin{array}{c}\text { Hawaiian } \\
\text { language terms }\end{array}$ & $44 \%$ & $64 \%$ & $47 \%$ & 3.2 & $22 \%$ \\
\hline $\begin{array}{l}\text { Cultural } \\
\text { practices }\end{array}$ & $25 \%$ & $59 \%$ & $24 \%$ & 2.8 & $26 \%$ \\
\hline $\begin{array}{c}\text { Indigenous } \\
\text { knowledge, or } \\
\text { ways of knowing }\end{array}$ & $43 \%$ & $69 \%$ & $33 \%$ & 2.9 & $29 \%$ \\
\hline $\begin{array}{l}\text { None of the } \\
\text { above }\end{array}$ & $0 \%$ & $0 \%$ & $9 \%$ & -- & $28 \%$ \\
\hline Other & $4 \%$ & $9 \%$ & $21 \%$ & -- & $14 \%$ \\
\hline
\end{tabular}

1Percentage of respondents who selected this choice. 2 Likert scale, ranging from 1 (very uncomfortable) to 5 (very comfortable). 
Faculty were asked to report their comfort level with each PBT practice on a Likert scale of 1 (very uncomfortable) to 5 (very comfortable), and these comfort levels broadly tracked with the types of strategies used. For example, the three most commonly used practices were local/regional data sets (79\%), local/regional experts as guest speakers $(59 \%)$ and field trips (53\%), and these strategies corresponded to the three highest comfort scores (4.6, 4.5, and 4.3, respectively) (Table 2). Similarly, the PBT strategies that faculty don't currently use but would like to use in the future (e.g., indigenous knowledge, cultural practices, community workdays and service learning) broadly correlated with lower comfort ratings (e.g., 2.8-3.5). In addition, the survey revealed that very few faculty (12\%) have received professional development (PD) training on PBT. This indicates that PD training aimed at increasing faculty comfort levels with specific PBT strategies would likely result in increased implementation of those strategies.

\section{Discussion \& Next Steps}

Teaching through a lens of place and culture can be richly rewarding; it can also be daunting, particularly for non-local faculty. In open-ended comments, faculty wrote: "It's hard to incorporate Hawaiian culture and indigenous knowledge into SOEST courses if you're not from here. First, I don't know enough to teach on these topics. But even if I did, I would be concerned about how students would react to being taught about these things from a haole [Caucasian, or non-local person]. That said, I think it would be a valuable addition to my course content." In recognition of these concerns, we propose a threelayered pyramid framework (Fig 1) for introducing PBT in college classes.

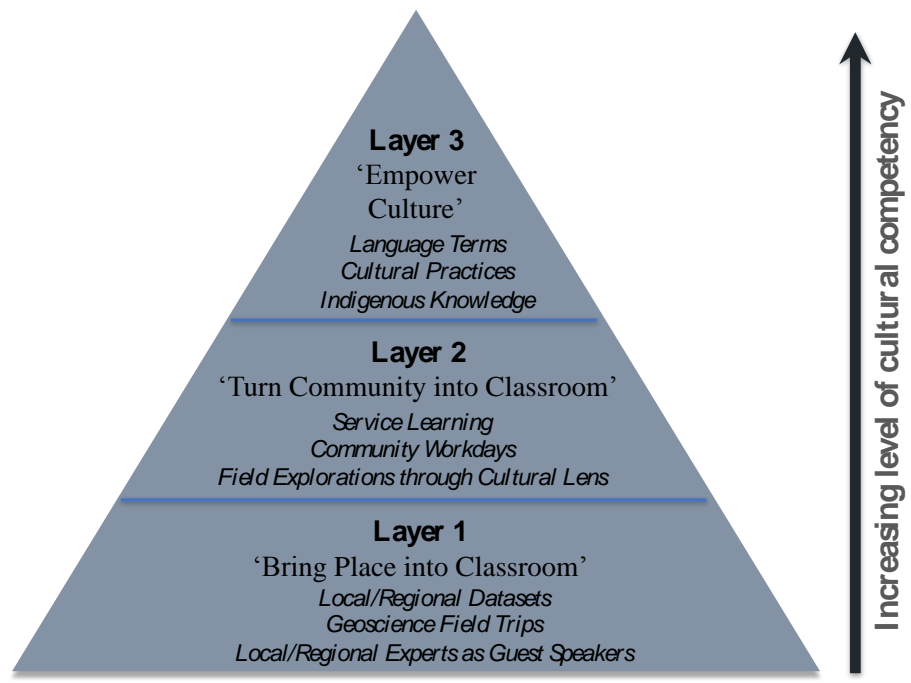

Fig. 1. Three-layered pyramid framework for introducing place-based teaching practices into the classroom. 
Faculty can start with the sample practices noted in the base layer, and progress upwards as their cultural competency and place attachment deepens. The base layer describes easy-toimplement PBT practices that bring place into the classroom, and that do not require deep cultural knowledge or community connections (e.g., using local/regional data sets or geoscience field trips). The middle layer involves turning the community into a classroom, and requires a higher level of community connections (e.g., service learning projects, field trips that integrate indigenous culture with Western science). The highest layer (e.g., incorporating indigenous knowledge or cultural practices) requires considerable cultural competency. While some non-local faculty might never feel it is culturally appropriate to explore this third layer on their own, they might feel more comfortable partnering with others, such as local or indigenous faculty or community members. In this way, faculty can progress along the continuum as their understanding deepens, and mitigate the inherent risk of cultural appropriation and mishaps. To encourage SOEST faculty to continue to use PBT in their courses, as well as to diversify their PBT practices, we have begun to assemble place-based geoscience resources (both physical and electronic). These include: field trip guides; local and regional datasets along with activities using these datasets; recommended community organizations and members to partner with; service learning opportunities; and a range of Hawaiian language and cultural resources. To date, we have established a physical lending library of books and videos on Hawai'i-relevant topics and place-based pedagogical practices for SOEST faculty. We furthermore have a pending proposal to build on these nascent efforts. If funded, we will: (1) create an expanded library to serve all UH faculty (not just SOEST); and (2) organize PD trainings, including fieldtrips and workshops, co-led by kupuna and other cultural experts, for SOEST and UH-wide faculty to further develop their sense of place. By doing so, we envision faculty incorporating more varied and meaningful PBT practices into their classrooms as their knowledge deepens and hence, making SOEST courses more attractive to NHPI students. In Fall 2020, we intend to evaluate the impact of these efforts on PBT by re-administering this same survey to SOEST students and faculty, and comparing these results to the Fall 2018 benchmark data (Tables 1-2) using standard statistical methods. Although each place is unique, the concept of PBT is universal and we invite collaborations from other research groups interested in testing this methodology in their locale.

\section{Conclusions}

We surveyed 59 faculty and 81 students at UH Manoa in Fall 2018 to explore PBT practices in SOEST. Survey results indicate that the overwhelming majority of faculty $(83 \%)$ and students $(78 \%)$ consider PBT an important and effective strategy for all students. Despite most SOEST faculty not being from Hawaii, virtually all use at least some PBT in their courses (e.g., 91\% report using local/regional data sets) with faculty comfort being 
key indicator of which PBT strategies they use. Importantly, students and faculty report wanting to see more PBT practices in future semesters. However, the PBT strategies that faculty would like to use in the future (e.g., indigenous knowledge and service learning) broadly correlated with lower comfort ratings (e.g., 2.9-3.5). We therefore propose a threelayered PBT framework, where faculty can progress upwards as their cultural competency deepens. Through providing geoscience resources and professional development opportunities, we empower faculty to further develop their sense of place, so they incorporate more diverse and culturally meaningful practices in future courses.

\section{Acknowledgements}

The U.S. National Science Foundation Awards \#1565950 and \#1557349 provided support for this study. We would like to thank SOEST faculty and students for participating in this research study.

\section{References}

Businger, A., Nogelmeier, M.P., Chinn, P.W.U., \& Schroeder, T. (2017). Hurricane with a history: Hawaiian newspapers illuminate an 1871 storm. Bulletin of the American Meteorological Society, 99, 137-147.

Cajete, G. (1994). Look to the mountain: An ecology of indigenous education. Skyland, NC: Kivaki Press.

Elder, J. (1998). Teaching at the edge. In: The Orion Society, ed., Stories in the land: A place-based environmental education anthology. Great Barrington, MA: The Orion Society, p. 1-15.

Gibson, B.A. \& Puniwai, N. (2006). Developing an archetype for integrating Native Hawaiian traditional knowledge with Earth system science education. Journal of Geoscience Education, 54, 287-294.

Institutional Research \& Analysis Office (IRAO) (2019). Available from: https://www.hawaii.edu/institutionalresearch/openingEnrollmentDemographics.action. Accessed Jan 25, 2019

Lemus, J.D., Seraphin, K.D., Coopersmith, A., \& Correa, C.K.V. (2014). Infusing traditional knowledge and ways of knowing into science communication courses at the University of Hawai'i. Journal of Geoscience Education, 62, 5-10.

Lincoln, N.K., \& Vitousek, P. (2017). Indigenous Polynesian agriculture in Hawai‘i. Oxford Research Encyclopedia of Environmental Science. DOI:10.1093/acrefore/9780199389414.013.376

Reano, D., \& Ridgway, K.D. (2015). Connecting geology and Native American culture on the reservation of Acoma Pueblo, New Mexico, USA. GSA Today, 25, 26-28.

Semken, S., Ward, E.G., Moosavi, S., \& Chinn, P.W.U. (2017) Place-based education in geoscience: Theory, research, practice, and assessment. Journal of Geoscience Education, 65, 542-562. 
Semken, S., \& Butler Freeman, C. (2008). Sense of place in the practice and assessment of place-based science teaching. Science Education, 92, 1042-1057.

Smythe, W.F., Hugo, R., \& MacAllister, S.M. (2017). Incorporation of traditional knowledge into geoscience education: An effective method of Native American instruction. Journal of Sustainability Education, 14, ISSN: 2151-7452.

Sobel, D. (2004). Place-based education: Connecting classrooms and communities. Great Barrington, MA: The Orion Society.

Stapp, W.B. et al. (1969). The concept of environmental education. The Journal of Environmental Education, 1, 30-31 